\title{
PERCEPÇÃO DE PROFESSORES PARAENSES SOBRE SAÚDE BUCAL INFANTIL
}

\author{
M. G. REBELLO ${ }^{1, *}$, C. M. L. OLIVEIRA ${ }^{2}$, A. J. S. NOGUEIRA ${ }^{3}$, D. B. CORRÊA ${ }^{4}$, F. K. REBELLO ${ }^{5}$ \\ ${ }^{1,3,4}$ Universidade Federal do Pará (UFPA), ${ }^{2}$ Escola Superior da Amazônia (ESAMAZ), ${ }^{5}$ Universidade Federal Rural \\ da Amazônia (UFRA) \\ monique_rebello@yahoo.com.br*
}

Submetido 28/08/2018 - Aceito 13/10/2018

DOI: $10.15628 /$ holos.2018.7675

\section{RESUMO}

O estudo analisa o nível de conhecimento dos professores da educação básica no estado do Pará quanto à saúde bucal infantil. Os professores selecionados para participar da pesquisa frequentavam o último período da graduação superior, em cursos de licenciatura, oferecidos pela Universidade Federal Rural da Amazônia (UFRA), polo Belém, no âmbito do Plano Nacional de Formação de Professores do Ensino Básico (PARFOR). Para aferir a percepção desses professoresalunos aplicou-se 104 questionários com questões fechadas, atingindo $80 \%$ de adesão do público-alvo em participar da pesquisa. As informações coletadas foram sistematizadas em um Banco de Dados no software Microsoft Excel 2010 para, na sequência, serem tratadas e analisadas. Constatou-se que os professores apresentam bom nível de informação sobre saúde bucal infantil, ainda que haja dúvidas em questões específicas como no caso dos dentes decíduos, indicação de uso de aparelhos ortodônticos para faixa etária de 8-10 anos e quanto à restauração de dentes. Esses resultados evidenciam que existe um importante campo de atuação conjunta a ser fortalecida entre cirurgiõesdentistas e professores, com vistas a reforçar o papel pedagógico do professor como agente formador do ser humano integral e, nesta perspectiva, contribuir na expansão de medidas de prevenção da saúde bucal de crianças em situação escolar. Iniciativas dessa natureza valorizam o desenvolvimento humano, bem como influenciam positivamente sobre o desempenho biopsicossocial desses jovens e de sua capacidade produtiva futura, elevando, portanto, a base do capital humano necessário para ampliar o desenvolvimento regional na Amazônia.

\section{PERCEPTION OF TEACHERS FROM THE STATE OF PARÁ ABOUT INFANT ORAL HEALTH}

\begin{abstract}
The study analyzes the level of knowledge of early childhood education teachers in the state of Pará, about infant oral health. The teachers selected to participate in the research attend the last term of an undergraduate teacher's program offered by Universidade Federal Rural da Amazônia (UFRA), in Belém, under the National Plan of Training for Basic Education Teachers (PARFOR). To measure perception of these teacher-students, 104 questionnaires were delivered with closed-ended questions, achieving $80 \%$ adhesion by the target public willing to participate in the research. The information collected was systematized in Data Bank using Microsoft Excel 2010 and eventually, treated and analyzed. It was found that teachers had a good level of information on infant oral health, despite some doubts on specific
\end{abstract}

questions such as deciduous tooth, indication of use of tooth braces for children between the ages of 8 to 10 including dental restoration. These results emphasize that there is an important field of joint activity to be strengthened between dentists and teachers, in order to enhance the teachers' pedagogical role as educators of human beings and, under this perspective, contribute for the expansion of preventive measures of oral health of school children. Initiatives of this nature value the integral human development, and influence positively on the biopsychosocial performance of these children and their future productive capacity, thus, improving the base of human capital necessary to increase regional development in the Amazon.

KEYWORDS: Human development, Integral education, Preventive Dentistry, Pediatric Dentistry, PARFOR. 


\section{APRESENTAÇÃO}

A odontologia vem passando por um processo de mudança. Anteriormente, a maior parte dos procedimentos eram cirúrgicos e restauradores, já nas últimas décadas um grande enfoque foi dado para a questão preventiva, principalmente na área infantil.

Essa atitude é fruto da própria evolução no conceito de saúde que passou a ver o indivíduo por seu estado de completo bem-estar físico, mental e social e não somente pela ausência de afecções e enfermidades. Essa visão acabou por propiciar uma maior interdisciplinaridade com profissionais fora da área da saúde.

Para a odontopediatria os professores da educação infantil e ensino fundamental podem ser um importante aliado na orientação de boas práticas de higiene bucal, ao lado da família, uma vez que passam muito tempo em contato com as crianças e, com conhecimento básico da área de saúde bucal, poderiam auxiliar os cirurgiões-dentistas no ofício da prevenção. Essa parceria entre dentistas e professores é, portanto, uma alternativa que tende a ser eficaz para a promoção da saúde bucal, desde que respaldada por uma diretriz assistida pelos órgãos competentes do setor.

Neste estudo, faz-se uma abordagem sobre o conhecimento e percepção dos professores a respeito da saúde bucal infantil. Pesquisas dessa natureza são importantes para verificar como está o nível de conhecimento dos profissionais da educação básica sobre o assunto, principalmente considerando o seu papel na formação de cidadãos. Da mesma forma, pode-se contribuir para incentivar a implementação de políticas e iniciativas no âmbito da prevenção e da qualidade de vida integral, a exemplo dos programas de saúde bucal nas escolas.

\section{REVISÃO DE LITERATURA}

A escola tem um papel importante na orientação e formação da cidadania das crianças, por isso também é um ambiente propício para desenvolver programas de saúde (Vasconcellos et al., 2001; Barros \& Maturana, 2005). Segundo Aquilante et al. (2003) a faixa etária mais apropriada para a criança adquirir hábitos alimentares corretos e de higiene é de quatro a sete anos, pois neste intervalo de idade o que é aprendido sobre modelos comportamentais são fixados mais profundamente e, portanto, mais difíceis de serem mudados.

A educação em saúde na escola possibilita à criança ter novos conhecimentos e ajuda nas mudanças de hábitos e atitudes indevidas observadas no cotidiano familiar (Pauleto, Pereira \& Cyrino, 2004). A criança pode ser também um agente multiplicador de informação sobre saúde dentro da sua família, pois o resultado dos seus atos pode influenciar o comportamento de forma positiva nos demais familiares (Saliba et al., 2003).

Os professores de educação infantil têm convívio diário com as crianças por longo período, com isso estabelecem vínculos afetivos com os alunos e também com familiares ou responsáveis pelas mesmas. Dessa forma, são as pessoas de maior contato com as crianças depois da família, se 
convenientemente preparados poderão observar possíveis problemas de saúde bucal nas crianças (Dalto \& Ferreira, 1998).

Na promoção de saúde nas escolas o professor é fundamental, pois é o que tem mais contato com as crianças e tem um papel importante na formação de cidadãos. Mas, para que o profissional da educação esteja preparado para desenvolver atividades sobre saúde bucal é preciso que antes tenha recebido informações e orientações corretas sobre o assunto. Quem está mais apto a passar esses ensinamentos são os cirurgiões-dentistas, que podem, de forma multidisciplinar, construir práticas pedagógicas sobre a temática (Ferreto \& Fagundes, 2009). Dessa forma, os professores se tornam um agente auxiliar para a construção de conhecimentos sobre saúde bucal, podendo contribuir para a formação de bons hábitos de saúde e higiene bucal e, posteriormente, melhorar estes índices na população brasileira (Vasconcelos et al., 2001).

\section{METODOLOGIA}

A pesquisa foi desenvolvida junto aos estudantes do último período dos Cursos de Licenciatura em Pedagogia (75 alunos entrevistados), Licenciatura em Ciências Naturais (17) e Licenciatura em Computação (16) matriculados nas turmas do Plano Nacional de Formação de Professores do Ensino Básico (PARFOR), ofertadas pela Universidade Federal Rural da Amazônia (UFRA), no polo Belém.

Neste público-alvo, aplicou-se um questionário com questões dicotômicas, com respostas de sim ou não, abrangendo temas básicos de odontopediatria para avaliar o nível de informação dos professores com atuação profissional na educação infantil e ensino fundamental no estado do Pará. Antes, ainda utilizando o mesmo instrumento de coleta de dados, levantou-se o perfil socioeconômico dos respondentes e outras questões referentes às fontes de obtenção de conhecimento por parte desses professores.

Ao todo foram aplicados 108 questionários, sendo que quatro foram descartados, pois os respondentes atuavam como professores do ensino médio. Assim, trabalhou-se com 104 entrevistas validas. Esse quantitativo (104 questionários) representa $80 \%$ do público que cursava o PARFOR/UFRA, polo Belém, em fevereiro de 2016, nas condições anteriormente descritas, sendo, portanto, uma amostra bastante representativa desse conjunto.

O PARFOR constitui-se em uma ação emergencial, criada em 2009 pelo Governo Federal, com o propósito de contribuir com a formação, em serviço, de professores da rede pública de ensino que ainda não possuem a graduação superior exigida pela Lei de Diretrizes e Bases da Educação Nacional (LDB). O Programa, portanto, tem como objetivo induzir e fomentar a oferta de educação superior, gratuita e de qualidade, para professores em exercício na rede pública (Brasil, 2016, Sousa et al., 2014).

O público-alvo dessa pesquisa assume, portanto, o status de professor-aluno, uma vez que a grande maioria exerce o ofício de professor leigo (sem formação superior) e aluno de curso superior na área da licenciatura, majoritariamente cursando Pedagogia $(69,44 \%)$. 
As informações coletadas foram sistematizadas em um Banco de Dados no software Microsoft Excel 2010 para, na sequência, serem tratadas e analisadas. Para efeito de comparação dos resultados obtidos nesta pesquisa adotou-se um paralelo com outro estudo realizado por Dalto e Ferreira (1998), no município de Londrina (PR), com estudantes do último período do curso de licenciatura em Pedagogia. Da mesma forma, os resultados foram confrontados com as recomendações técnico-científicas da área de odontopediatria obtidas na literatura especializada.

\section{RESULTADOS E DISCUSSÃO}

\subsection{Perfil socioeconômico dos entrevistados}

Na Tabela 1 apresentam-se os dados socioeconômicos dos professores entrevistados. Observa-se que dos 104 entrevistados 82,69\% eram mulheres e 17,31\% homens. As faixas etárias entre 31 e 40 anos e entre 41 e 50 anos eram as mais representativas com $31,73 \%$, cada. Os jovens, entre 20 e 30 anos, respondiam por 10,58\% do contingente de professores-alunos.

Tabela 1: Perfil socioeconômico dos entrevistados.

\begin{tabular}{|c|c|c|}
\hline Variável & Frequência absoluta & (\%) \\
\hline \multicolumn{3}{|l|}{ Sexo } \\
\hline Feminino & 86 & $82,69 \%$ \\
\hline Masculino & 18 & $17,31 \%$ \\
\hline \multicolumn{3}{|l|}{ Idade } \\
\hline $20-30$ anos & 11 & $10,58 \%$ \\
\hline $31-40$ anos & 33 & $31,73 \%$ \\
\hline $41-50$ anos & 33 & $31,73 \%$ \\
\hline 51 ou mais & 11 & $10,58 \%$ \\
\hline Não informou & 16 & $15,38 \%$ \\
\hline \multicolumn{3}{|l|}{ Estado civil } \\
\hline Solteiro & 34 & $32,69 \%$ \\
\hline Casado & 39 & $37,50 \%$ \\
\hline União estável & 23 & $22,12 \%$ \\
\hline Divorciado & 4 & $3,85 \%$ \\
\hline Viúvo & 2 & $1,92 \%$ \\
\hline Não informou & 2 & $1,92 \%$ \\
\hline \multicolumn{3}{|l|}{ Renda } \\
\hline Até 1 salário mínimo & 23 & $22,12 \%$ \\
\hline Mais de 1-4 salário mínimo & 62 & $59,62 \%$ \\
\hline Mais de 4-6 salário mínimo & 9 & $8,65 \%$ \\
\hline Mais de 6-10 salário mínimo & 2 & $1,92 \%$ \\
\hline Mais de $10-15$ salário mínimo & 1 & $0,96 \%$ \\
\hline Mais de 15 salário mínimo & 2 & $1,92 \%$ \\
\hline Não informou & 5 & $4,81 \%$ \\
\hline \multicolumn{3}{|l|}{ Onde trabalha } \\
\hline Escola Privada & 3 & $2,88 \%$ \\
\hline
\end{tabular}


Escola Pública

Desempregados
90

11
$86,54 \%$

$10,58 \%$

Fonte: dados da pesquisa.

A maioria dos entrevistados trabalhavam em escolas públicas (86,54\%). Apenas $2,88 \%$ lecionavam em escolas privada e $10,58 \%$ estavam desempregados na ocasião da pesquisa. As pessoas que possuíam renda de até um salário mínimo (SM) equivaliam a 22,12\%. Os que estavam na faixa entre mais de um SM até quatro SM representavam 59,62\% e, apenas, 1,92\% recebiam mais que $15 \mathrm{SM}$.

Estes professores tinham atuação em 88 municípios paraenses, tendo maior representatividade os municípios de Belém, Ananindeua, Benevides, Augusto Corrêa e Castanhal, e outros da mesorregião do Nordeste Paraense, uma das áreas de colonização mais antigas da Amazônia e com problema no seu nível de desenvolvimento humano e social (Rebello \& Homma, 2017). Essa capilaridade de atuação dos professores acaba sendo relevante para efeito de multiplicação do conhecimento sobre saúde bucal em municípios carentes, sobretudo, onde a relação dentista $x$ paciente é desfavorável.

\subsection{Professores como agentes promotores da saúde bucal}

No Gráfico 1, abaixo, apresenta-se a participação relativa quanto à fonte de obtenção de informações pelos respondentes, quanto aos procedimentos necessários para a correta escovação dos dentes. 


\section{$49,04 \%$}

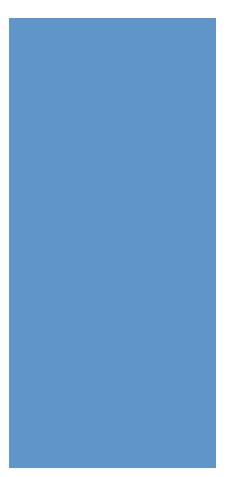

Dentista
$39,42 \%$

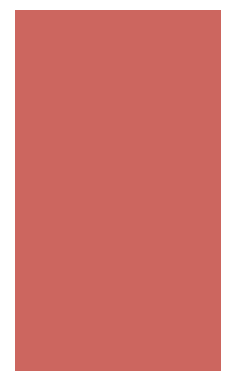

Seus pais
$10,58 \%$

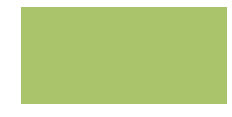

Professores
$3,85 \%$

$2,88 \%$

Outros Programa de TV

Gráfico 1: Fonte de obtenção de informações quanto aos procedimentos de escovação dentária pelos entrevistados (\%).

Fonte: dados da pesquisa.

Nota: $5,77 \%$ dos informantes marcaram mais de uma opção.

A partir do Gráfico 1, constata-se que $49,04 \%$ dos professores pesquisados receberam orientações sobre escovação dos dentes por meio de cirurgiões-dentistas, seguido pelos pais $(39,42 \%)$, professores $(10,58 \%)$, programas de televisão $(2,88 \%)$. Cerca de $3,85 \%$ apontaram outras fontes de informação, como palestras e Internet.

A percepção dos professores quanto a importância do ensino de conteúdo básico sobre saúde bucal nas escolas é apresentando no Gráfico 2 .

$80,77 \%$

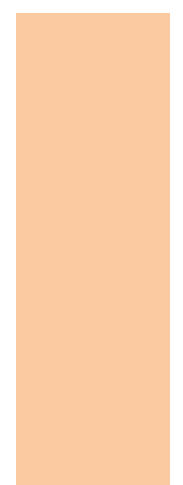

$15,38 \%$

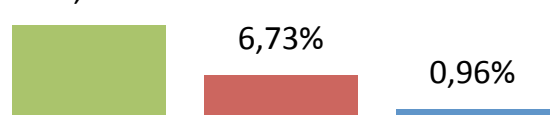

Sim, realizado em parceria entre professores, dentistas e familiares.

Sim, mas tem que ser feito por um dentista.

Sim, feito por professores capacitados no assunto.

não, Escola não é o lugar adequado.

Gráfico 2: Percepção dos entrevistados quanto à importância do ensino sobre saúde bucal na escola (\%). Fonte: dados da pesquisa.

Nota: 3,84\% dos informantes marcaram mais de uma opção. 
Para $80,77 \%$ dos entrevistados a parceria entre os professores, dentista e a família é importante para repassar ensinamentos quanto à saúde bucal. Para 15,38\% essa responsabilidade deve ser exclusivamente do dentista. Outros $6,73 \%$ disseram que os professores podem agir nessa área, desde que estejam capacitados para isso. Apenas $0,96 \%$ disseram que a escola não é o lugar adequado para tratar desse assunto.

Nessa perspectiva de integração de ações entre os profissionais da área da saúde e da educação, Filgueira et al. (2016) recomendam a interdisciplinaridade e a relação horizontal. Segundo os autores, poderia ser estabelecida uma relação entre os conteúdos ensinados nas salas de aula e a questão da saúde, de uma maneira contextualizada ao conteúdo disciplinar tradicional. Como exemplo, poderia incluir a discussão sobre as doenças bucais infectocontagiosas como a cárie dentária nas aulas de biologia, discussão sobre a determinação social das doenças bucais e a influência do território nas aulas de geografia, e também incentivar trabalhos de pesquisa para discussão sobre o assunto em classe, com o objetivo de sensibilizá-los da melhor forma sobre o tema saúde-doença-cuidados.

Essa abordagem, no longo prazo, a partir da ampliação do conhecimento na sociedade, pode contribuir para elevar o nível de saúde bucal e qualidade de vida da população, permitindo, desta forma, somar esforços para elevar a formação do capital humano em áreas do estado do Pará que ainda enfrentam esse problema e, assim, atingir patamares mais elevados de desenvolvimento. Particularmente quanto ao problema da saúde bucal, em alguns dos municípios paraenses mais pobres, ainda se observa alta incidência de indivíduos desdentados, refletindo uma imagem de abandono e pobreza. A ausência de dentes pode ser tomada como uma consequência da pobreza absoluta e da falta de cuidados de saúde pública (Rebello, 2012). Essa, portanto, é uma chaga que precisa ser resolvida.

Na Tabela 2, por sua vez, são apresentadas 11 questões básicas sobre saúde bucal infantil para posicionamento dos professores. Nelas os entrevistados podiam responder, dicotomicamente, ou seja, afirmativa ou negativamente (sim ou não) sobre a situação-problema a partir do seu nível de conhecimento. 
Tabela 2: Questões básicas de odontopediatria formuladas aos professores (\%).

\begin{tabular}{|c|c|c|c|}
\hline Questões & Sim & Não & $\begin{array}{l}\text { Não } \\
\text { respondeu }\end{array}$ \\
\hline 1. Até quatro anos é normal a criança chupar chupeta? & 7,69 & 92,31 & - \\
\hline $\begin{array}{l}\text { 2. É certo deixar a criança mamar mamadeira por toda a } \\
\text { infância? }\end{array}$ & 6,70 & 93,30 & - \\
\hline 3. O leite da mamadeira deve ser adoçado com açúcar? & 21,10 & 76,00 & 2,90 \\
\hline $\begin{array}{l}\text { 4. Uma criança que respira o tempo todo com a boca aberta } \\
\text { tem problema de saúde bucal? }\end{array}$ & 95,20 & 3,80 & 1,00 \\
\hline 5. Dente escuro é sinônimo de dente cariado? & 48,10 & 47,10 & 4,80 \\
\hline $\begin{array}{l}\text { 6. O hábito de apoiar objetos como caneta nos dentes é } \\
\text { prejudicial? }\end{array}$ & 92,30 & 3,85 & 3,85 \\
\hline $\begin{array}{l}\text { 7. Há necessidade de cuidados odontológicos a um bebê } \\
\text { mesmo antes de ter dente? }\end{array}$ & 82,70 & 17,30 & - \\
\hline $\begin{array}{l}\text { 8. Dentes separados em crianças de 8-10 anos são sinais de que } \\
\text { precisarão usar aparelho? }\end{array}$ & 59,60 & 37,50 & 2,90 \\
\hline 9. Há materiais odontológicos que evitam a cárie? & 83,60 & 13,50 & 2,90 \\
\hline 10. Deve-se escovar os dentes sempre após se alimentar? & 98,00 & 2,00 & - \\
\hline 11. Dentes de leite cariados devem ser restaurados? & 63,50 & 36,50 & - \\
\hline
\end{tabular}

Fonte: dados da pesquisa.

\subsubsection{Uso de Chupeta}

Quanto ao uso da chupeta, 92,31\% dos professores mostraram ter conhecimento quanto aos malefícios causados por seu uso prolongado. Esse resultado foi melhor que o obtido na pesquisa de Dalto e Ferreira (1998) quando 57,44\% dos entrevistados disseram não ser normal o uso da chupeta até os quatro anos.

Segundo a Associação Brasileira de Odontopediatria (2009) e o Ministério da Saúde (2006) a idade para eliminação do uso da chupeta pela criança é até os três anos. Porém reconhecem que o ideal seria remover gradualmente este hábito até os dois anos de idade, pois há maior chance de auto-correção de possíveis desarmonias nas arcadas dentárias, em consequência do hábito de sucção de chupeta.

A gravidade da má oclusão dentária depende da frequência, intensidade e duração do hábito. Quando o hábito de sucção continua até os quatro anos, há uma maior prevalência de problemas oclusais como mordida cruzada posterior, mordida aberta anterior e sobressaliência excessiva. Quando a criança abandona o hábito ainda na primeira dentição, existe a possibilidade 
da mordida aberta se autocorrigir (Silva, 2006). Para ocasionar alterações maxilares por uso de chupeta, são necessários, no mínimo, dois anos de sucção.

No estudo de Mesomo e Losso (2004) 93\% das crianças maiores de três anos que faziam uso de chupetas apresentaram mordida aberta. Outros trabalhos também relataram o alto índice de crianças com mordida aberta que utilizava chupeta após os três anos (Ferreira et al., 2001).

\subsubsection{Uso da mamadeira por toda a infância}

O prolongamento do uso da mamadeira não é aconselhado pelos odontopediatras. Nesta pesquisa constatou-se que $93,30 \%$ dos entrevistados demonstraram, de alguma forma, conhecer essa orientação. A pesquisa de Dalto e Ferreira (1998) obteve um resultado parecido, onde 91,37\% falaram não ser normal o uso da mamadeira por toda a infância.

A mamadeira deve ser utilizada apenas para o aleitamento artificial. Outros líquidos como água, chá e suco, devem ser oferecidos no copo. A mamadeira quando usada nunca deve ser associado ao sono, ou seja, não pode deixar o bebê dormir enquanto está se alimentando ( $A B O$, 2009).

\subsubsection{Uso do açúcar na mamadeira}

A sacarose é um dos maiores responsáveis pela cárie, então quanto mais cedo à criança tiver contato com alimento adoçado artificialmente maior pode ser o risco de cárie precoce. 0 estudo revelou que $76,00 \%$ dos entrevistados tinham conhecimento sobre esse assunto, ou seja, reconheciam que o leite não deve ser adoçado. A pesquisa de Dalto e Ferreira (1998) encontrou o mesmo resultado (75,89\%). A ingestão frequente de açúcares e outros carboidratos (sucos, bebidas ácidas) e o contato prolongado dessas substâncias com os dentes são fatores de risco para o desenvolvimento da cárie. Assim, em se tratando de bebê e criança de pouca idade, a mamadeira é o principal veículo de ingestão de alimentos cariogênicos. Por isso, segundo $A B O$ (2009), o consumo de açúcar deve ser evitado nos dois primeiros anos de vida.

Fraiz, Bezerra e Walter (2013) mostram que o uso da mamadeira com leite adoçado, achocolatados, chás adoçados e sucos pode resultar na cárie precoce na infância. Afirmam, também, que crianças que tem alimentação ligada ao sono com produtos que contenham açúcares, associada à ausência de escovação, tem mais chance de ter cárie precocemente, pois geralmente leva a grandes destruições dentárias.

\subsubsection{Respirador bucal}

A respiração bucal é um problema que $95,20 \%$ dos entrevistados tinham conhecimento, número parecido com o encontrado na pesquisa de Dalto e Ferreira (1998), onde 93,45\% afirmaram que a respiração pela boca é um problema. 
A respiração bucal pode ter causas multifatoriais, podendo ser de natureza obstrutiva como hipertrofia das tonsilas palatinas, hipertrofia das adenóides, desvio de septo nasal, pólipos nasais, alergias respiratórias, posição de dormir e aleitamento artificial, ou então ser decorrentes de hábitos bucais deletérios, como sucção digital ou de chupeta, dependendo da intensidade e da frequência do hábito, pode, deformar a arcada dentária e alterar o equilíbrio facial (Fransson et al., 2006).

Também é possível perceber algumas características físicas em pessoas com respiração bucal como face alongada, olheiras, olhos caídos, lábios entreabertos e ressecados, narinas estreitas, relação oclusal com tendência a má oclusão, estreitamento do arco superior, palato alto e bochechas com musculaturas hipotônicas (Cintra et al., 2000).

Quanto antes for feito o diagnóstico de um respirador bucal maior é a chance de sucesso do tratamento, que deve ser realizado, multidisciplinarmente, entre dentista, otorrino, fonoaudiólogo, fisioterapeuta e, às vezes, pela psicologia e nutrição para alcançar resultados satisfatórios (Miranda et al., 2002; Menezes et al., 2006).

\subsubsection{Manchas no dente decíduo}

A questão da aparência dos dentes mostrou ser um assunto que causa muita dúvida entre os entrevistados, pois $48,10 \%$ disseram que dente escuro é sinônimo de cárie, contra 47,10\% que acreditavam que não e 4,80\% preferiram não responder. A pesquisa de Dalto e Ferreira (1998) apontou que $57,14 \%$ entenderam que o escurecimento dos dentes é cárie. Os resultados mostram que a população tem um julgamento precipitado achando que manchas escuras nos dentes são sempre cárie.

\subsubsection{Hábito nocivo de apoiar objetos}

Para 92,30\% dos entrevistados apoiar objetos nos dentes pode trazer algum prejuízo. No estudo de Dalto e Ferreira (1998), 89,88\% dos entrevistados responderam sim a essa pergunta, 0 que mostra um resultado equivalente quando se comparam as duas pesquisas.

Os hábitos orais podem forçar os dentes e estruturas dento-alveolares. O que define o grau do dano que pode ser ocasionado é a sua frequência, duração e intensidade. Algumas deformações dento-alveolares e esqueléticas que podem ocorrer são: sobresaliência acentuada, sobremordida reduzida ou mordida aberta, mordida cruzada posterior ou altura facial aumentada (ABO, 2009).

\subsubsection{Odontologia para bebê}

A maioria dos entrevistados reconheceu a importância da odontologia para os bebês, já que $82,70 \%$ entende que há necessidade de levar o bebê ao dentista mesmo antes de nascer os primeiros dentes. Na pesquisa de Dalto e Ferreira (1998) houve um resultado ainda melhor $90,77 \%$. 
Segundo a $A B O$ (2009) a primeira consulta do bebê ao dentista deve ser feita o quanto antes, pois ele irá fazer um exame mais detalhado da cavidade bucal. Fazendo o correto acompanhamento o profissional pode diagnosticar também alguma alteração bucal como cistos, tumores, lesões em tecidos moles causados por bactérias, fungos e vírus. É importante também fazer a avaliação dos freios dos lábios e da língua. Isso pode evitar problemas futuros, por exemplo, o freio da língua, quando é encurtado (anquiloglossia), pode interferir nos seus movimentos e dificultar a sucção e deglutição do bebê, atrapalhando sua amamentação e futuramente a mastigação e fala. Além de fazer o exame clínico o dentista também passa aos pais orientações preventivas referentes à frequência do aleitamento materno, uso de mamadeira, hábitos dietéticos e higienização bucal, antes do surgimento do primeiro decíduo.

\subsubsection{Diastema em crianças de 8-10 anos}

Apenas $37,50 \%$ dos professores disseram que os dentes separados não são sinais de que a criança precisa usar aparelho, enquanto que 59,60\% acreditam que sim. A pesquisa de Dalto e Ferreira (1998) apesar de ter tido um melhor resultado nessa questão, também apresentou um baixo entendimento sobre o assunto, pois apenas 39,88\% afirmaram não ser, necessariamente, um problema.

Para fazer a correta indicação do uso de aparelhos é necessário realizar uma análise ortodôntica, pois pequenos espaços entre os dentes podem ser normais nessa idade.

\subsubsection{Materiais que evitam Cárie}

Cerca de $83,60 \%$ dos professores acreditam que existe material que podem evitar a cárie, $13,50 \%$ acham que não possui e $2,90 \%$ preferiram não responder. O número de pessoas que conhecem esse poder de prevenir a cárie na pesquisa de Dalto e Ferreira (1998) foi maior (91,96\%).

A ABO (2009), afirma que apesar dos esforços, a cárie dentária continua sendo um problema de saúde pública, e as evidências científicas indicam que um importante fator para sua prevenção é a utilização diária de dentifrício fluoretado com 1.000 ppm de flúor desde a erupção do primeiro dente. Os fluoretos podem ser encontrados em cremes dentais, enxaguante bucais, algumas bebidas industrializadas e na própria água de abastecimento.

\subsubsection{Escovação}

Nesse quesito a resposta foi quase unânime, pois $98,00 \%$ dos entrevistados disseram ser importante realizar a escovação dos dentes após a alimentação. Na pesquisa de Dalto e Ferreira (1998) esse número foi um pouco menor (95,53\%).

Atualmente, considera-se a cárie uma doença complexa, polimicrobiana, uma disbiose. Assim, a lesão de cárie é observada somente quando ocorre um desequilíbrio no meio bucal, o que favorece a acidificação do biofilme dentário em decorrência do metabolismo dos carboidratos 
da dieta por microorganismos residentes (Cruz et al., 2017). Por isso é importante ter uma alimentação equilibrada e escovar os dentes após as refeições para dificultar a ação dos microorganismos.

\subsubsection{Restaurações de dentes decíduos}

No aspecto de restauração em dentes decíduos, 63,50\% afirmaram que eles deve ser restaurados, número menor quando comparado com os resultados de Dalto e Ferreira (1998) onde $74,40 \%$, reconheciam a importância de preservar os dentes de leite.

Os dentes decíduos não têm apenas função estética, eles são muito importantes para uma mastigação harmônica e também para a manutenção de espaço para os dentes permanentes. Por isso a perda precoce de um dente, provavelmente, ocasionará uma mudança na direção de erupção do permanente, com isso poderá ter problema no posicionamento dentário (Nogueira, 2015). Assim, é importante preservar o dente decíduo até sua esfoliação.

\subsection{Estratégias para a promoção da saúde bucal a partir da escola}

Quando comparado os resultados desta pesquisa com o estudo desenvolvido por Dalto e Ferreira (1998), percebe-se que os resultados atuais são melhores em quase todos os quesitos levantados. Isso, certamente, está relacionado com a ampliação do conhecimento da população sobre saúde bucal, visto que transcorreram quase 20 anos entre a realização das duas pesquisas, ainda que efetuadas em municípios e regiões distintas, e pelo fato da experiência de vida assumida pelo público-alvo deste estudo, também, ter influenciado, uma vez que, possivelmente ${ }^{1}$, seja mais ampla em decorrência da idade e por haver passado pela vivência da maternidade e paternidade, o que, certamente, os aproximou mais dessas questões.

Para se obter índices de saúde bucal cada vez melhores é importante que haja investimento e estímulo para o ensino do assunto nas escolas públicas e privadas. Os resultados deste estudo, portanto, pode contribuir para orientar políticas públicas para ampliar ações de prevenção da saúde bucal entre estudantes do ensino infantil e fundamental nas escolas paraenses. Iniciativas dessa natureza podem ser alavancadas pelo Conselho Regional de Odontologia, em parceria com os Cursos de Odontologia e as Secretárias de Saúde Pública e de Educação do estado e municípios paraenses.

Nessa linha, palestras educativas, escovodromos, cartilhas e material didático apropriado para as escolas seriam muito bem-vindos para elevar o nível de conhecimento e de prática de higiene bucal eficaz junto às crianças e suas famílias. Da mesma forma, a elaboração de material didático de uso em diversas disciplinas e áreas do conhecimento também seria relevante.

Ações dessa natureza são estratégicas para valorizar o desenvolvimento humano integral, bem como influenciar, positivamente, sobre o desempenho biopsicossocial das crianças e jovens e

\footnotetext{
${ }^{1}$ Uma limitação na pesquisa de Dalto e Ferreira (1998), quanto a não apresentar o perfil socioeconômico dos respondentes, impossibilita ser categórico nessa afirmação.
} 
de sua capacidade produtiva futura, elevando, portanto, a base do capital humano necessário para ampliar o desenvolvimento regional na Amazônia, particularmente no estado do Pará.

\section{CONCLUSÕES}

A pesquisa evidenciou que os professores entrevistados possuem, de modo geral, um bom conhecimento sobre saúde bucal. Em contrapartida, ainda há dúvida em alguns tópicos específicos como no caso dos dentes decíduos, indicação de aparelho ortodôntico para a faixa etária de 8-10 anos, quanto aos aspectos estéticos dos dentes e sobre cárie.

Essa deficiência pode ser mitigada com a implementação de estratégias de integração multidisciplinar entre professores e cirurgiões-dentistas na prevenção de saúde bucal junto às crianças na fase escolar. Para isso, deve-se buscar um amplo programa para reforçar essa prática nas escolas.

Assim, os cursos de licenciatura poderiam ensinar conteúdos de educação em saúde bucal, de forma a capacitar os futuros professores para melhor desenvolver práticas adequadas de educação em saúde na escola, contribuindo para formação integral do cidadão.

\section{AGRADECIMENTOS}

Os autores são gratos aos professores-alunos do PARFOR/UFRA que gentilmente aceitaram participar da pesquisa respondendo ao questionário apresentado. Institucionalmente, também, agradecem a Universidade Federal Rural da Amazônia (UFRA), particularmente aos coordenadores do Plano Nacional de Formação do Ensino Básico (PARFOR).

\section{REFERÊNCIAS}

Associação Brasileira de Odontopediatria (2009). Manual de referência para procedimentos clínicos em odontopediatria. 432 p.

Aquilante, A. G., Almeida, B. S., Martins Castro, R. F., Chavier, C. R. G., Sales Peres, S. H. C., Bastos, J. R. M. (2003). A importância da educação em saúde bucal para pré-escolares. Revista de Odontologia da UNESP, São Paulo, v.32, p. 139-145.

Barros, L. O., Maturana, L. A. (2005). Saúde na escola e os parâmetros curriculares nacionais: analisando a transversalidade em uma escola fluminense. Revista Digital - Buenos Aires, año 10. n82. Disponível em: < http://efdeportes.com/efd82/saude.htm>. Acesso em: 10 abr. 2018.

BRASIL. Decreto № 8.752, de 9 de maio de 2016 (2016). Disponível em:<http://www. planalto. gov.br/ccivil_03/Ato2015-2018/2016/Decreto/D8752.htm\#art19>. Acesso em: 18 abr. 2018. 
Cintra, C. F. S. C., Castro, F. F. M., Cintra, P. P. V. C (2000). As alterações oro-faciais apresentadas em pacientes respiradores bucais. Rev Bras Alerg Imunopatol. 23 (2): 78-83.

Cruz, L. R., D’Hyppolito, I. M., Barjafidalgo, F., Oliveira, B. H. (2017). Cárie é transmissível? Tipo de informação sobre transmissão da cárie em crianças encontrada através da ferramenta de busca Google. Rev. Bras. Odontol., v.74, n.1, p. 70-3.

Dalto, V., Ferreira, M. L. (1998). Os professores como agentes promotores da saúde bucal. Semina. Londrina, v. 19, ed. Especial, p. $47-50$.

Ferreira, S. H., Ruschel, H. C., De Bacco, G., Ulian, J. (2001). Estudo da prevalência da mordida aberta anterior em crianças de zero a cinco anos de idade nas creches municipais de Bento Gonçalves (RS). J Bras Odontopediatr Odontol Bebê, 4(17): 74-9.

Ferreto, L. E., Fagundes, M. E. (2009). Conhecimentos e práticas em saúde bucal de professores dos centros municipais de educação infantil de Francisco Beltrão, PR, Brasil. Revista Faz Ciência, v.11, n.13, p. 143-158.

Filgueira, A. C. G., Machado, F. C. A., Amaral, B. A., Lima, K. C., Assunção, I. V. (2016). Saúde bucal de adocescentes escolares. Holos, Ano 32, Vol. 1. p. 161-172.

Fraiz, F. C., Bezerra, A. C. B., Walter, L. R. F. (2013). Assistência odontológica ao bebê - enfoque doença cárie dentária. In: Massara, M. L., Rédua, P. Manual de referência para procedimentos clínicos em odontopediatria. São Paulo: ABO. Disponível em: <http://www.abodontopediatria. org.br/manual1/Capitulo-12-Assistencia-Odontologica-ao-Bebe---Enfoque-Doenca-Carie-Dentaria. pdf>. Acesso em: 18 abr. 2018.

Fransson, J. M. D., Magnani, M. B. B. A., Nouer, D, F., Siqueira, V. C. V., Lunardi, N. (2006). Estudo cefalométrico comparativo entre respiradores nasais e predominantemente bucais. Rev Bras Otorrinolagol, 72(1):72-82.

Menezes, V. A., Leal, R. B., Pessoa, R. S.; Pontes, R. M. E. S. (2006). Prevalência e fatores associados à respiração oral em escolares participantes do projeto Santo Amaro-Recife. Rev Bras Otorrinolaringol, 72(3): 394-399.

Mesomo, C., Losso, E. M. (2004). Avaliação dos efeitos do uso prolongado de chupetas convencionais e ortodônticas sobre a dentição decídua. Rev Ibero-am Odontopediatr Odontol Bebê, 7(38): 360-4.

Ministério da Saúde (2006). Caderno de Atenção Básica n¹7. Brasília: MS.

Miranda, P. P. C., Mashuda, S. Y. K., Periotto, M. C.; Araújo, R. J. H. (2002). Enfoque multidisciplinar na síndrome do respirador bucal. Rev Paulista de Odontol, 24(3): 4-8.

Nogueira, A. J. S. (2015). Perdas dentárias precoces e sua importância para as dentições. 1. Ed. Belém: Paka-Tatu.

Pauleto, A. R. C., Pereira, M. L. T., Cyrino, E. G. (2004). Saúde bucal: uma revisão crítica sobre programações educativas para escolares. Ciência e saúde coletiva, v.9, n.1, p. 121-130. 
Rebello, F. K. (2012). Da lenha ao óleo de Palma: a transformação da agricultura no Nordeste Paraense. Tese (Doutorado em Ciências Agrárias) - Universidade Federal Rural da Amazônia, Belém.

Rebello, F. K., Homma, A. K. O. (2017). História da colonização do Nordeste Paraense: Uma reflexão para o futuro da Amazônia. Belém: Edufra.

Saliba, N. A., Pereira, A. A., Moimaz, S. A. S., Garbin, C. A. S., Arcieri, R. M. (2003). Programa de educação em saúde bucal: a experiência da Faculdade de Odontologia de Araçatuba - UNESP. Odontologia Clín. Científ., 2 (3): 197-200, set/dez.

Silva, E. L (2006). Hábitos bucais deletérios. Rev. Para. Med., v. 20, n.2.

Sousa, S. N. F., Aguiar, K. C., Rebello, F. K., Cardoso, C. M. (2014). Perfil socioeducacional dos alunos do PARFOR/UFRA: o caso do polo Belém. In: Anais do XII Seminário Anual de Iniciação Científica da UFRA. Belém: UFRA, 2014. Disponível em:<https://mega.nz/\#F!6FBmmD5B!OVfxW uakDxZwl Q62om2keg!XdgQCbrK>. Acesso em: 18 abr. 2018.

Vasconcelos, R., Matta, M. L., Pordeus, I. A., Paiva, S. M. (2001). Escola: um espaço importante de informação em saúde bucal para a população infantil. PGR Pós-Grad Rev Fac Odontol, v.4, n.3, set/dez. 